\title{
Association Between M235T-AGT and $I / D$-ACE Polymorphisms and Carotid Atheromatosis in Hypertensive Patients: A Cross-Sectional Study
}

\author{
OANA MOCAN ${ }^{1 *}$, DAN RADULESCU ${ }^{2}$, ELENA BUZDUGAN $^{2 *}$, ANGELA COZMA $^{3 *}$, \\ DANIEL CORNELIU LEUCUTA ${ }^{4 *}$ and LUCIA MARIA PROCOPCIUC ${ }^{5}$ \\ 1 "Iuliu Hatieganu” University of Medicine and Pharmacy, Faculty of Medicine, Cluj-Napoca, Romania; \\ ${ }^{2}$ Department of Internal Medicine, $5^{\text {th }}$ Medical Clinic, \\ "Iuliu Hațieganu” University of Medicine and Pharmacy, Cluj-Napoca, Romania; \\ ${ }^{3}$ Department of Internal Medicine, $4^{\text {th }}$ Medical Clinic, \\ “Iuliu Hațieganu” University of Medicine and Pharmacy, Cluj-Napoca, Romania; \\ ${ }^{4}$ Department of Medical Informatics and Biostatistics, \\ “Iuliu Hațieganu” University of Medicine and Pharmacy, Cluj-Napoca, Romania; \\ ${ }^{5}$ Department of Medical Biochemistry, \\ “Iuliu Hațieganu” University of Medicine and Pharmacy, Cluj-Napoca, Romania
}

\begin{abstract}
Background/Aim: The renin-angiotensinaldosterone system (RAAS) may be implicated in carotid atheromatosis (CA) development. We aimed to assess the relationship of M235T-angiotensinogen (AGT) and insertion/deletion of angiotensin conversion enzyme (I/DACE) genotypes with $C A$ in patients with essential hypertension (EHT). Patients and Methods: We determined the M235T-AGT and I/D-ACE genotypes, using PCR-RFLP methods, in 162 hypertensive subjects from three tertiary regional medical centers. The relationship between the studied RAAS gene polymorphisms and CA was assessed by multiple logistic regressions. Results: Hypertensive patients carrying the MT/TT235-AGT and MT235-AGT genotypes had a 2.17-fold $(p=0.033)$ and 2.24-fold $(p=0.036)$ increased risk to develop CA, respectively. These genotypes, MT/TT 235-AGT $(O R=2.17, p=0.033)$ and MT235-AGT $(O R=2.24$, $p=0.036)$, remain independent risk factors for $C A$ in hypertensive patients according to the multivariate model.
\end{abstract}

This article is freely accessible online.

*These Authors contributed equally to this work.

Correspondence to: Daniel Corneliu Leucuta, 6 Pasteur Street, 400349, Cluj-Napoca, Romania. Tel: +40 264597256 int 2502, e-mail: dleucuta@umfcluj.ro

Key Words: Essential hypertension, carotid atheromatosis, M235TAGT genotype, $I / D$-ACE genotype.
Conclusion: There is a statistically significant association between M235T-AGT and CA, when adjusting for several confounders and controlling for hypertension.

Essential hypertension (EHT) is associated with cardiovascular risk factors, such as carotid atheromatosis (CA), dyslipidemia, obesity, left ventricular hypertrophy $(\mathrm{LVH})$, and presents a high risk for ischemic coronary and cerebrovascular events (1-4).

According to the World Health Organization (WHO), ischemic cardiovascular diseases are responsible for $31 \%$ of all deaths worldwide. Stroke and myocardial infarction (MI) represent $80 \%$ of all deaths of ischemic vascular cause (5).

$\mathrm{CA}$ and the increase in carotid intima-media thickness (cIMT) in the carotid-vertebral axis are manifestations of atherosclerotic disease and diagnostic markers for ischemic heart disease (IHD) and ischemic cerebrovascular disease $(6,7)$.

The genetic polymorphisms of the renin-angiotensinaldosterone system (RAAS) are associated with uncontrolled EHT $(8,9)$. RAAS influences atherosclerosis (ATS) through oxidative stress, an increase in NADPH activity, reactive oxygen species production and low-density lipoprotein cholesterol (LDL-C) peroxidation $(10,11)$.

The components of RAAS are angiotensinogen (AGT), angiotensin-converting enzyme (ACE), angiotensin I (AngI), angiotensin II (AngII), angiotensin II type 1 receptor (AngII R1) and angiotensin II type 2 receptor (AngII R2) (12). AGT is secreted by the liver and is converted to AngI upon the action of renin (REN). ACE converts AngI to AngII, 
stimulates aldosterone secretion from the adrenal cortex, and influences blood pressure (BP) (13-15). ACE is a risk factor for ischemic cerebrovascular ischemic events, high levels of plasma ACE determines atheromatosis and increased cIMT. High levels of plasma AngII induces proliferation of arteriolar smooth muscle, collagen deposition and apoptosis of smooth muscle cells (16-18). ACE activity in arterial endothelial and smooth muscle cells is increased, contributing to the development of atherosclerotic lesions, independently of BP values or lipid profile (19).

Met235Thr (M235T-T704C) is a point mutation in the gene encoding AGT, which is associated with EHT and ATS, through the induction of endothelial dysfunction and increase in vascular wall inflammation (20). Meta-analyses have reported that Caucasian patients diagnosed with EHT, carriers of the MT235 heterozygous genotype or the TT235 homozygous genotype, had higher AGT levels compared to MM235 homozygotes. In some studies, patients carrying the TT235 genotype were diagnosed with malignant hypertension (HT) $(21,22)$.

$I / D$ represents the insertion/deletion of a fragment of the ACE gene, which results in an increase in plasma ACE levels and activity. This genetic variation closely correlates with EHT $(23,24)$.

There is a genetic predisposition of pateints with the $M 235 T$-AGT and I/D-ACE genotypes to IHD, ischemic stroke, EHT, and diabetes mellitus (DM) $(5,25,26)$.

The aim of our study was to analyze the M235T-AGT and $I / D$-ACE gene polymorphisms in patients with EHT, and their relationship with $\mathrm{CA}$, as predictors of ischemic cerebrovascular events.

\section{Patients and Methods}

Study design and setting. We designed a prospective cross-sectional study in EHT patients from the ambulatory, internal medicine, and cardiology wards of three tertiary regional medical centers $\left(4^{\text {th }}\right.$ Medical Clinic, $5^{\text {th }}$ Medical Clinic, and Polaris Hospital in ClujNapoca, Romania), between June 2015 - December 2017.

The study included 162 patients diagnosed with EHT (on treatment), as well as patients newly diagnosed with EHT. Systolic BP (SBP) and diastolic BP (DBP) were measured 5 minutes after the beginning of the examination. According to EHT management guidelines, three successive measurements were performed 2-5 min apart, in sitting or supine position, with a manual blood pressure monitor. EHT was defined according to guidelines at values higher than or equal to $140 / 90 \mathrm{mmHg}$, glycemia was considered increased at values over $100 \mathrm{mg} / \mathrm{dl}$, high total cholesterol (TC) was considered at values $>200 \mathrm{mg} / \mathrm{dl}$, increased low-density lipoprotein cholesterol (LDL-C) was considered at values higher than $100 \mathrm{mg} / \mathrm{dl}$, hypertriglyceridemia (HTG) was considered at triglyceride (TG) values over $150 \mathrm{mg} / \mathrm{dl}$.

A detailed history was recorded for each patient including age, gender, and body mass index (BMI) (weight/height $-\mathrm{kg} / \mathrm{cm}^{2}$ ).

The following laboratory tests were performed in the patients included in the study: TC, TG, high-density lipoprotein cholesterol (HDL-C), LDL-C, renal function (urea, creatinine), liver function [alanine transaminase (ALT) and aspartate transaminase (AST)], using standard laboratory methods.

Associated risk factors, such as dyslipidemia, DM, and nonalcoholic hepatic steatosis (NAHS), were monitored for the presence of the metabolic syndrome. The general objective of the examination was aimed the detection of the presence of possible signs of EHT-mediated organ involvement (cardiovascular, neurological changes) and other causes of secondary HT, such as the presence of neurofibromatosis or hyperthyroidism.

Patients who refused participation in the study, patients with secondary HT, with acute or chronic renal disease, with a glomerular filtration rate (GFR) below $30 \mathrm{ml} / \mathrm{min} / 1.72 \mathrm{~m}^{2}$, with functional New York Heart Association (NYHA) class III and IV heart failure, cancer disease and liver failure, or alcohol-induced hepatic steatosis (HS) were excluded from the study.

Written consent was obtained from all participants before their inclusion in the study. The study was approved by the Ethics Committee of "Iuliu Hatieganu" University of Medicine and Pharmacy (study no. 333/2.06.2015).

Carotid ultrasonography. At the time of recruitment, all patients underwent B-mode Doppler ultrasound of the carotid-vertebral axis, abdominal ultrasound, using Samsung H60 (Samsung Medison, Seoul, South Korea), and Aloka Alpha 7 (Aloka Medical Company Ltd., Tokyo, Japan) ultrasound systems, with 3-14 MHz linear probes and 1-7 MHz convex probes, respectively. The participants were examined in the supine position. The presence of ATS plaques was examined in transverse and longitudinal sections in the common carotid arteries (CCA), carotid bulb, internal carotid artery (ICA) and external carotid artery (ECA), bilaterally.

For cIMT and CA examination, measurements in 3 CCA locations, where no ATS plaques were present and at 1.5-1 cm distance from the CCA bifurcation were performed. Patients were diagnosed as having CA if they presented a cIMT greater than or equal to $1 \mathrm{~mm}$ or more than $50 \%$ focal narrowing of the vessel wall or ATS plaques. The severity of stenosis was classified: no stenosis, mild $<50 \%$, moderate $50-70 \%$, severe $70-99 \%$, and occlusion.

Also, the presence or absence of HS was examined by abdominal ultrasound, according to standard examination protocols: 1) attenuation of the image quickly within $4-5 \mathrm{~cm}$ of depth, 2) echogenic diffusely but particularly important to note brightness within the first $2-3 \mathrm{~cm}$ of depth, 3) liver uniformly heterogeneous, and 4) thick subcutaneous depth $(>2 \mathrm{~cm})$. No complimentary examinations for the diagnosis of HS were performed (liver puncture biopsy, abdominal CT, FibroScan), because the aim of this study was not to analyze the relationship between gene polymorphism and HS.

Genetic determinations. For genetic determinations, venous blood was collected in EDTA vacutainers. Genomic DNA was isolated from peripheral leukocytes using a DNA isolation kit (Quick-DNAMiniprep Kit-Zymo Research Corporation, Freiburg, Germany).

Identification of M235T-AGT genotypes. The patients' M235T-AGT genotypes were identify using the following specific primers: forward primer, 5'CAGGGTGCTGTCCACACTGGACCCC-3' and reverse primer, 5'-CCGTTTGTGCAGGGCCTGGCTCTCT-3'. Amplification was performed in an iCycler (Bio-Rad Life Science, Hercules, CA, USA) in $25 \mu \mathrm{l}$ reaction mixture and comprised $20 \mathrm{ng}$ DNA, $0.2 \mu \mathrm{M}$ primers, $2.0 \mathrm{mM} \mathrm{MgCl}_{2}, 200 \mu \mathrm{M}$ dNTPs, $2 \mathrm{U}$ Taq 
Table I. Comparison of patient characteristics between essential hypertension subjects with and without carotid atheromatosis.

\begin{tabular}{|c|c|c|c|}
\hline Carotid atheromatosis & $\begin{array}{l}\text { Yes } \\
(73)\end{array}$ & $\begin{array}{l}\text { No } \\
(89)\end{array}$ & $p$-Value \\
\hline Age (years), mean (SD) & $64.4(9.08)$ & $52.67(12.44)$ & $<0.001$ \\
\hline Age $\geq 60$ years (yes), $\mathrm{n}(\%)$ & $55(75.34)$ & $33(37.08)$ & $<0.001$ \\
\hline Gender (Female), n (\%) & $33(45.21)$ & $50(56.18)$ & 0.164 \\
\hline Gender (Male), n (\%) & $40(54.79)$ & $39(43.82)$ & \\
\hline BMI $\left(\mathrm{kg} / \mathrm{cm}^{2}\right)$, mean $(\mathrm{SD})$ & $29.43(4.25)$ & $29.54(4.21)$ & 0.87 \\
\hline Weight status & & & 0.704 \\
\hline Normal weight & $9(12.33)$ & $13(14.61)$ & \\
\hline Obesity & $34(46.58)$ & $45(50.56)$ & \\
\hline Overweight & $30(41.1)$ & $31(34.83)$ & \\
\hline $\begin{array}{l}\text { LDL cholesterol }(\mathrm{mg} / \mathrm{dl}) \text {, } \\
\text { mean }(\mathrm{SD})\end{array}$ & $125.82(33.71)$ & $127.85(36.72)$ & 0.717 \\
\hline $\begin{array}{l}\text { LDL cholesterol } \\
>100 \mathrm{mg} / \mathrm{dl}, \mathrm{n}(\%)\end{array}$ & $50(68.49)$ & $56(62.92)$ & 0.458 \\
\hline $\begin{array}{l}\text { Total cholesterol }(\mathrm{mg} / \mathrm{dl}) \text {, } \\
\text { mean }(\mathrm{SD})\end{array}$ & $199.62(46.99)$ & $204.97(40.58)$ & 0.438 \\
\hline $\begin{array}{l}\text { Total cholesterol } \\
>200 \mathrm{mg} / \mathrm{dl}, \mathrm{n}(\%)\end{array}$ & $39(53.42)$ & $51(57.3)$ & 0.621 \\
\hline $\begin{array}{l}\text { Triglycerides }(\mathrm{mg} / \mathrm{dl}), \\
\text { mean }(\mathrm{SD})\end{array}$ & $158.14(77.75)$ & $130.83(71.25)$ & 0.021 \\
\hline $\begin{array}{l}\text { Triglycerides }>150 \mathrm{mg} / \mathrm{dl}, \\
\mathrm{n}(\%)\end{array}$ & $34(46.58)$ & $28(31.46)$ & 0.049 \\
\hline cIMT, n (\%) & $45(61.64)$ & $7(7.87)$ & $<0.001$ \\
\hline $\begin{array}{l}\text { Left ventricular } \\
\text { hypertrophy, n (\%) }\end{array}$ & $55(75.34)$ & $46(51.69)$ & 0.002 \\
\hline Hepatic steatosis, n (\%) & $58(79.45)$ & $56(62.92)$ & 0.022 \\
\hline $\begin{array}{l}\text { Glucose basal level, } \\
\text { median (IQR) }\end{array}$ & $102(92-113)$ & $96(90-105)$ & 0.033 \\
\hline Diabetes mellitus, n (\%) & $14(19.18)$ & $9(10.11)$ & 0.1 \\
\hline
\end{tabular}

BMI: Body mass index- weight $(\mathrm{kg}) /$ height $(\mathrm{cm})^{2}$; LDL-cholesterol: low-density lipoprotein cholesterol; cIMT: increased intima-media thickness; SD: standard deviation; IQR: interquartile range.

polymerase in specific buffer, 10X Taq buffer with $\left(\mathrm{NH}_{4}\right)_{2} \mathrm{SO}_{4}[750$ $\mathrm{mM}$ tris- $\mathrm{HCl}\left(\mathrm{pH} 8.8\right.$ at $\left.25^{\circ} \mathrm{C}\right), 200 \mathrm{mM}\left(\mathrm{NH}_{4}\right)_{2} \mathrm{SO}_{4}, 0.1 \%(\mathrm{v} / \mathrm{v})$ Tween 20]. The amplification program included an initial denaturation stage of $10 \mathrm{~min}$ at $95^{\circ} \mathrm{C}$, followed by 34 amplification cycles with a denaturation stage of $10 \mathrm{~s}$ at $94^{\circ} \mathrm{C}$, a primer hybridization stage of $20 \mathrm{~s}$ at $64^{\circ} \mathrm{C}$, an elongation stage of $20 \mathrm{~s}$ at $72^{\circ} \mathrm{C}$, followed by a final elongation stage of $5 \mathrm{~min}$ at $72^{\circ} \mathrm{C}$. The amplified fragment of $165 \mathrm{bp}$ was subjected to enzymatic digestion in $10 \mu \mathrm{l}$ mixture with $5 \mathrm{U}$ of the specific restriction enzyme Tth111I, for $3 \mathrm{~h}$ at $65^{\circ} \mathrm{C}$. The normal $M 235$ allele is not digested while the mutated T235 allele forms two fragments of 141 and $24 \mathrm{bp}$ (1).

Identification of I/D-ACE genotypes. To identify patients' I/D-ACE genotypes, the forward 5'-CTGGAGACCACTCCCATCCTTTCT3' and reverse 5'-GATGTGGCCATCACATTCGTCAGC-3' primers were used. Amplification was performed in an iCycler (Bio-Rad) in $25 \mu \mathrm{l}$ reaction mixture, and comprised $20 \mathrm{ng}$ DNA, $0.2 \mu \mathrm{M}$ primers, $2.0 \mathrm{mM} \mathrm{MgCl} 2,200 \mu \mathrm{M}$ dNTPs, $2 \mathrm{U}$ Taq polymerase in specific buffer, 10X Taq buffer with $\left(\mathrm{NH}_{4}\right)_{2} \mathrm{SO}_{4}[750 \mathrm{mM}$ tris- $\mathrm{HCl}(\mathrm{pH} 8.8$ at $\left.25^{\circ} \mathrm{C}\right), 200 \mathrm{mM}\left(\mathrm{NH}_{4}\right)_{2} \mathrm{SO}_{4}, 0.1 \%$ (v/v) Tween 20]. The amplification program included an initial denaturation stage of 5 min at $95^{\circ} \mathrm{C}$, followed by 34 amplification cycles with a denaturation stage of $10 \mathrm{~s}$ at $94^{\circ} \mathrm{C}$, a primer hybridization stage of $20 \mathrm{~s}$ at $69^{\circ} \mathrm{C}$, an elongation stage of $20 \mathrm{~s}$ at $72^{\circ} \mathrm{C}$, followed by a final elongation stage of $5 \mathrm{~min}$ at $72^{\circ} \mathrm{C}$. The $I$-ACE allele generates a 390 bp fragment, while the $D$-ACE allele generates a $290 \mathrm{bp}$ fragment (1).

The amplified and enzymatic digestion fragments were visualized by UV light through migration in agarose gels stained with ethidium bromide $10 \mathrm{mg} / \mathrm{ml}$.

All PCR-RFLP reagents were from Fermentas (Thermo Fischer Scientific Inc., Waltham, MA, USA) and Jena Bioscience (Analytik Jena AG, Jena, Thuringia, Germany), except for primers, which were from Eurogentec (Kaneka Eurogentec S.A., Liege Science Park, Seraing, Liege, Belgium).

Bias. We took special care to use objective methods to assess the two genetic polymorphisms, outcome (CA), and confounders, as explained above. We excluded important confounding pathologies, and we used multiple logistic regressions to control for known confounders.

Statistical analysis. Categorical variables were described by counts and percentages. We used means and standard deviations or medians and interquartile ranges for continuous data (for normal and skewed data). The Hardy-Weinberg equilibrium was assessed using an exact test. The associations between single nucleotide polymorphisms (SNP) and CA were assessed using the codominant, dominant, recessive, overdominant, and log-additive models, showing the odds ratio, $p$-value and the Akaike information criterion of the model. Next, we built several logistic regression models to explore the relationship between polymorphisms and CA. We built four models, two for each polymorphism (one for codominant and one for dominant models). Each model included the polymorphisms that were adjusted for age, gender, HS, LDL-C. The adjusted variables were chosen based on literature search and on the results found in univariate analysis. For all the models, we checked the presence of multicollinearity, misspecifications (Stukel test for interaction and Osius-Rojek test), and their goodness of fit (using HosmerLemeshow test). For continuous variables, we checked the linearity with the log-odds (using a general additive model with smoothing). The results of the regression are expressed as odds ratios with $95 \%$ confidence intervals. For all statistical tests, we showed the twotailed $p$-value with a 0.05 level of significance.

All statistical analyses were performed in $\mathrm{R}$ environment for statistical computing and graphics (R Foundation for Statistical Computing, Vienna, Austria), version 3.6.2. For genetic associations, we used the package SNPassociation 1.9-2.

\section{Results}

Our study included 162 patients with EHT with a mean age of $58.01(\mathrm{SD}=12.43)$ years, range 23-86 years. Of the 162 patients diagnosed with EHT, 73 had CA. Of these, 40 $(54.79 \%)$ were men and $33(45.21 \%)$ were women. The age of hypertensive patients with CA was significantly older compared to that of hypertensive patients without CA $(p<0.001)$. The results obtained showed a statistically significantly higher number of hypertensive patients with CA aged over 60 years compared to those without CA $(p<0.001)$. 
in vivo $34: 2811-2819(2020)$

Table II. M235T-AGT model associations with carotid atheromatosis in essential hypertensive subjects.

\begin{tabular}{|c|c|c|c|c|c|c|c|c|c|}
\hline Model & With CA & $\%$ & Without CA & $\%$ & OR & $95 \%$ CI lower & $95 \%$ CI upper & $p$-Value & AIC \\
\hline \multicolumn{10}{|l|}{ Codominant } \\
\hline$M M 235$ & 15 & 20.5 & 32 & 36.0 & 1.00 & & & 0.09134 & 224.2 \\
\hline MT235 & 41 & 56.2 & 39 & 43.8 & 0.45 & 0.21 & 0.95 & & \\
\hline TT235 & 17 & 23.3 & 18 & 20.2 & 0.50 & 0.20 & 1.22 & & \\
\hline \multicolumn{10}{|l|}{ Dominant } \\
\hline$M M 235$ & 15 & 20.5 & 32 & 36.0 & 1.00 & & & 0.02988 & 222.3 \\
\hline MT235-TT235 & 58 & 79.5 & 57 & 64.0 & 0.46 & 0.23 & 0.94 & & \\
\hline \multicolumn{10}{|l|}{ Recessive } \\
\hline MM235-MT235 & 56 & 76.7 & 71 & 79.8 & 1.00 & & & 0.63787 & 226.8 \\
\hline$T T$ & 17 & 23.3 & 18 & 20.2 & 0.84 & 0.39 & 1.77 & & \\
\hline \multicolumn{10}{|l|}{ Overdominant } \\
\hline MM235-TT235 & 32 & 43.8 & 50 & 56.2 & 1.00 & & & 0.11747 & 224.5 \\
\hline MT235 & 41 & 56.2 & 39 & 43.8 & 0.61 & 0.33 & 1.14 & & \\
\hline \multicolumn{10}{|l|}{ Log-additive } \\
\hline $0,1,2$ & 73 & 45.1 & 89 & 54.9 & 0.69 & 0.44 & 1.07 & 0.09751 & 224.3 \\
\hline
\end{tabular}

CA: Carotid atheromatosis; OR: odds ratio; CI: confidence interval; AIC: Akaike information criterion.

No significant differences were found regarding gender $(p=0.164)$ and weight status (BMI) $(p=0.87)$ between hypertensive patients with and without CA. Regarding the lipid profile, there were no statistically significant differences in plasma LDL-C $(p=0.717)$ and TC $(p=0.438)$ levels between the two groups of hypertensive patients, with and without CA. In contrast, a statistically significant association between the presence of CA and HTG was observed $(p=0.021)$. Also, basal glycemia was evaluated, the difference being statistically significant between the group of hypertensive patients with CA compared to those without CA $(p=0.033)$.

Hypertensive patients with CA had TG $>130 \mathrm{mg} / \mathrm{dl}$ $(p=0.049)$, an increase in cIMT $>1 \mathrm{~mm}$ in the carotid axis $(p<0.001)$, and LVH $(p=0.002)$ in a significantly higher proportion than hypertensive patients without CA.

The characteristics of hypertensive patients with and without CA are shown in Table I.

Distribution of RAAS genotypes in the study groups. The distribution of M235T-AGT genotypes in the group of hypertensive patients with CA compared to the group of hypertensive patients without CA was as follows: MT235 (56.2\% vs. $43.8 \%$ ), TT235 (23.35 vs. 20.2\%), MM235 (20.5\% vs. $36 \%$ ). The M235T-AGT genetic variant was statistically significantly associated with CA in the dominant model $(p<0.029)$, but not in the other models (codominant, recessive, log-additive).

Regarding the $I / D$-ACE gene variant, the distribution of genotypes in the group of hypertensive patients with CA compared to those without CA was as follows: I/D (20.5\% vs. $29.2 \%), \mathrm{D} / \mathrm{D}(37 \%$ vs. $34.8 \%)$, I/I (42.5\% vs. 36), but the differences were not statistically significant in the codominant model.

Genotype distribution and the relationship of M235T-AGT and $I / D$-ACE with CA in hypertensive patients are presented in Tables II and III.

We found deviations from Hardy-Weinberg equilibrium for the I/D-ACE polymorphism, but not for M235T-AGT (Table IV).

For the M235T-AGT polymorphism and for the I/D-ACE gene variant, the codominant and dominant models in relation to CA were examined.

With regard to M235T-AGT polymorphism, in the dominant model, the chance for a patient to have CA was 2.17 times $(95 \% \mathrm{CI}=1.08-4.53)$ higher for the MT235-TT235 genotype compared to $M M 235$, the association being statistically significant $(p=0.0298)$. The association was maintained even after adjustment for confounders (age, sex, HS, and LDL-C), with 2.3 times $(95 \% \mathrm{CI}=1.05-5.26)$ higher chance of having CA $(p=0.041)$ for patients carrying MT235-TT235 genotypes. In the codominant model, the chance for a patient to have CA was 2.24 times $(95 \% \mathrm{CI}=1.07-4.86)$ higher in the case of patients carrying the MT235 genotype compared to carriers of the MM235 genotype, the association being statistically significant $(p=0.036)$, and 2.01 times higher for carriers of the TT235 genotype compared to patients carrying the MM235 genotype, but the association was not statistically significant. Following adjustment for confounders, the chance for a patient to have CA was 2.32 times higher in the case of carriers of the MT235 genotype compared to carriers of the MM235 genotype, but the association was not statistically significant $(p=0.052)$. 
Table III. I/D-ACE model associations with carotid atheromatosis in essential hypertensive subjects.

\begin{tabular}{|c|c|c|c|c|c|c|c|c|c|}
\hline Model & With CA & $\%$ & Without CA & $\%$ & OR & $95 \%$ CI lower & $95 \%$ CI upper & $p$-Value & AIC \\
\hline \multicolumn{10}{|c|}{ Codominant } \\
\hline$I / I$ & 31 & 42.5 & 32 & 36.0 & 1.00 & & & 0.4281 & 227.3 \\
\hline$I / D$ & 15 & 20.5 & 26 & 29.2 & 1.68 & 0.75 & 3.76 & & \\
\hline$D / D$ & 27 & 37.0 & 31 & 34.8 & 1.11 & 0.54 & 2.27 & & \\
\hline \multicolumn{10}{|l|}{ Dominant } \\
\hline$I / I$ & 31 & 42.5 & 32 & 36.0 & 1.00 & & & 0.3979 & 226.3 \\
\hline$I / D-D / D$ & 42 & 57.5 & 57 & 64.0 & 1.31 & 0.70 & 2.48 & & \\
\hline \multicolumn{10}{|l|}{ Recessive } \\
\hline$I / I-I / D$ & 46 & 63.0 & 58 & 65.2 & 1.00 & & & 0.7760 & 226.9 \\
\hline$D / D$ & 27 & 37.0 & 31 & 34.8 & 0.91 & 0.48 & 1.74 & & \\
\hline \multicolumn{10}{|c|}{ Overdominant } \\
\hline$I / I-D / D$ & 58 & 79.5 & 63 & 70.8 & 1.00 & & & 0.2043 & 225.4 \\
\hline$I / D$ & 15 & 20.5 & 26 & 29.2 & 1.60 & 0.77 & 3.31 & & \\
\hline \multicolumn{10}{|c|}{ Log-additive } \\
\hline $0,1,2$ & 73 & 45.1 & 89 & 54.9 & 1.06 & 0.74 & 1.52 & 0.7494 & 226.9 \\
\hline
\end{tabular}

CA: Carotid atherosclerosis; OR: odds ratio; CI: confidence interval; AIC: Akaike information criterion.

For the $I / D$-ACE gene variant, no statistically significant association with CA was observed without adjustment for confounding variables nor after adjustment. The chance of having $\mathrm{CA}$ was 0.6 times higher in carriers of the $I / D$ genotype compared to the $I / I$ genotype without adjustment, and 0.48 times higher after adjustment for confounders. The chance to have CA was 0.9 times higher in carriers of the $D / D$ genotype compared to the $I / I$ genotype without adjustment, and 0.7 times higher after adjustment for confounders. The chance to have CA was 0.76 times higher in carriers of the $D / D$ or $I / D$ genotype compared to carriers of the $I / I$ genotype without adjustment, and 0.61 times higher after adjustment for confounders.

The results of univariate and multivariate regression analysis are presented in Table V.

\section{Discussion}

Genetic and environmental factors (race, ethnicity, geographical region) influence the development and progression of ATS $(27,28)$. Some studies confirm the relationship of the $I / D$-ACE gene polymorphism with IHD and EHT, while others refute this association (29-35). Therefore, there are few and contradictory data regarding the relationship between $\mathrm{CA}$ and the gene variations involving RAAS.

Therefore, the aim of our study was to determine the relationship between the M235T-AGT, I/D-ACE gene variants, and EHT as predictors of CA.

It has been established that M235T-AGT and I/D-ACE gene variants play a role in the etiology of IHD and the development of MI in Caucasian and Japanese subjects (24,
Table IV. Hardy-Weinberg equilibrium exact test p-values for M235T$A G T$ and I/D-ACE polymorphisms in essential hypertension subjects.

\begin{tabular}{lrc}
\hline $\begin{array}{l}\text { Single nucleotide } \\
\text { polymorphism }\end{array}$ & With CA & Without CA \\
\hline$M 235 T$-AGT & 0.3541 & 0.3845 \\
$I / D$-ACE & $<0.0001$ & 0.0001 \\
\hline
\end{tabular}

CA: Carotid atheromatosis.

$36,37)$. Ethnicity, geographical area, and environmental factors influence this association (21).

Hazzani et al. (2014) have demonstrated that the TT235 genotype increases susceptibility to coronary disease in the Egyptian population, independently of other risk factors such as smoking, DM, lipid profile (38). Min et al. (2019) have mentioned that a Chinese population carrying the M235TAGT genetic variant was susceptible to MI (39). Jeng et al. (1999), in a study on a population of Chinese origin, have shown that in patients with EHT, the TT235 genotype might be considered a risk factor for the development of $\mathrm{LVH}$, but not CA (40).

The mechanism of association between M235T-AGT and I/D-ACE genetic variants with EHT and CA is not clear. Bonfim-Silva et al. (2016) have shown that a Brazilian population of Caucasian origin had an increased risk for EHT in the case of carriers of the TT235 genotype, possibly due to the high plasma AGT concentration in association with this genotype (21). However, Pontremoli et al. (2000) have shown that carriers of the M235T-AGT genetic variation had increased SBD and DBD values and presented 
in vivo $34: 2811-2819(2020)$

Table V. Univariate and multivariate logistic regressions predicting carotid atheromatosis in association with M235T-AGT and I/D-ACE genetic variations.

\begin{tabular}{|c|c|c|c|c|c|c|}
\hline Parameters & OR unadjusted & $(95 \% \mathrm{CI})$ & $p$-Value & OR adjusted* & $(95 \% \mathrm{CI})$ & $p$-Value \\
\hline $\begin{array}{l}\text { M235T-AGT } \\
\text { (MT235heterozygous vs. MM235 negative) }\end{array}$ & 2.24 & $(1.07-4.86)$ & 0.036 & 2.32 & $(1.01-5.52)$ & 0.052 \\
\hline $\begin{array}{l}\text { M235T-AGT } \\
\text { (TT235homozygous vs. MM235 negative) } \\
I / D \text {-ACE }\end{array}$ & 2.01 & $(0.82-5.04)$ & 0.128 & 2.27 & $(0.81-6.54)$ & 0.121 \\
\hline $\begin{array}{l}\text { (I/Dheterozygous } v s . I / I \text { negative }) \\
I / D \text {-ACE }\end{array}$ & 0.6 & $(0.26-1.32)$ & 0.207 & 0.48 & $(0.18-1.22)$ & 0.13 \\
\hline $\begin{array}{l}\text { (D/Dhomozygous vs. I/I negative) } \\
\text { M235T-AGT-dominant }\end{array}$ & 0.9 & $(0.44-1.84)$ & 0.77 & 0.7 & $(0.31-1.59)$ & 0.402 \\
\hline$(T T, M T$ vs. MM) & 2.17 & $(1.08-4.53)$ & 0.033 & 2.3 & $(1.05-5.26)$ & 0.041 \\
\hline$I / D$-ACE-dominant $(D / D, I / D v s . I / I)$ & 0.76 & $(0.4-1.44)$ & 0.398 & 0.61 & $(0.29-1.25)$ & 0.181 \\
\hline
\end{tabular}

BMI: Body mass index; AGT: angiotensinogen; LDL-C: low-density lipoprotein cholesterol; OR: odds ratio; CI: confidence interval; *adjusted for age, gender, hepatic steatosis.

CA (41). Chapman et al. (2001), in a study conducted in a population of Chinese origin, determined the risk of developing CA and found an increase in cIMT in the case of patients carrying the M235T-AGT genetic variant (42). Furthermore, studies conducted by Min et al. (2019) and Van Rijn et al. (2007) have established that the M235T-AGT gene polymorphism plays an independent role in the pathophysiology and evolution of CA, through the increase in cIMT and progression of ATS, even if EHT is controlled by treatment $(39,43)$. The study conducted by Kretowski et al. (2007) has demonstrated that type $1 \mathrm{DM}$ associated with TT235 genotype could lead to CA progression (44).

With regard to the $I / D$-ACE genetic variant it has been reported that it is involved in the development and progression of IHD, LVH, CA and cerebrovascular disease $(36,41,45)$. In addition, in a study carried out by Zhang et al. (2004), the D/D-ACE genotype was considered an independent risk factor and predisposes to cerebral microatheromatous disease, as well as to lacunar stroke (46). Forgo et al. (2018), in a meta-analysis including 9800 Asian and Caucasian hypertensive patients diagnosed with cerebrovascular ischemic disease, type 1 and $2 \mathrm{DM}$, have demonstrated that the $I / D$-ACE genotype was associated with an increase in cIMT $>1 \mathrm{~mm}$ (5). A comparative study in a European and Asian population conducted by Xia et al. (2019) ihas shown that the $D$ allele was associated with an increased risk of ATS in European compared to Asian subjects (28). In a study performed by Islam et al. in Finland in 2006, which included healthy subjects, no association of the presence of $I / D$-ACE and M235T-AGT polymorphisms with the predisposition to EHT or CA was demonstrated (47).

Our prospective cross-sectional study showed a statistically significant association between M235T-AGT and $\mathrm{CA}$ in the dominant model. The odds of having CA were 2.17 higher for the MT-TT genotype than for the $M M$ genotype of the M235T-AGT polymorphism in hypertensive patients, even after adjustment - OR=2.3 (95\% CI=1 .05-5.26) - for confounders (age, gender, HS, LDL-C). Univariate analysis showed that the MT235-TT235 genotypes represent risk factors for $\mathrm{CA}$ in the case of hypertensive patients. Multivariate analysis implies that the MT235-TT235 genotype of the M235T-AGT polymorphism is an independent risk factor for CA in hypertensive patients.

We found no statistically significant association between the $I / D$-ACE genetic variation and $\mathrm{CA}$ in hypertensive patients, either in univariate or in multivariate analyses.

A number of studies have evaluated other risk factors for CA independently of the patient's genetic profile. The study conducted by Arnett et al. (1998) in hypertensive middleaged patients without a history of CA, non-carriers of $D$ ACE or T235-AGT alleles reported CA progression in these patients (48).

The study carried out by Min et al. (2019) has confirmed the association of CA with metabolic syndrome and HS (39). Also, the study performed by Targher et al. (2006) has confirmed that CA reflects generalized ATS and ischemic vascular disease and is influenced by age, sex, the geographical area, smoking, EHT, type 2 DM, high LDL-C (49). Moreover, it has been shown that pathophysiologically, the process of aging, hypercholesterolemia, EHT, DM are responsible for the development of CA and increase in cIMT (50-52). Forgo et al. (2018) have demonstrated that risk factors associated with EHT influence the location of the carotid ATS plaque, DM, and smoking cause ATS in the carotid bulb and high LDL-C induces ATS in the ICA (5). Our study observed an association between CA and age $(p<0.001)$, HTG $(p=0.049)$ and NAHS $(p=0.022)$.

The limitations of our study refer to the fact that our study sample consisted of patients with EHT from regional tertiary centers. Thus the results are generalizable to this type of 
population. We had a limited number of exclusion criteria, and this is an argument in favor of generalization.

The strength of our study is the fact that we had a good sample size, having enough power to show the association between M235T-AGT and ATS. The association was present in our sample that used exclusion criteria to limit the influence of important confounders. Furthermore, the observed relationship held even after adjustment for potential confounders.

In the future, we aim to include a greater number of patients in the study and to extend investigations by analyzing more genetic variants associated with RAAS as risk factors for $\mathrm{CA}$ in hypertensive patients.

\section{Conclusion}

Our results showed an association between M235T-AGT and CA, after adjustment for several confounders and controlling for HT, the study being conducted only in hypertensive subjects. The presence of similar results in other studies is a good argument in favor of this association. Nevertheless, ATS is a complex process, and the importance of this finding and its relationships with other characteristics associated with it represent an open field for different studies.

\section{Conflicts of Interest}

There are no known conflicts of interest regarding this study.

\section{Authors' Contributions}

OM: Conception of the study, performed collection of subjects, clinical work and ultrasound procedures, preparation of the database, drafted the manuscript; DR, EB: conception of the study, performed collection of subjects, clinical work and ultrasound procedures; AC: performed collection of subjects, clinical work and ultrasound procedures; DCL: performed the statistical analysis, contribution to manuscript preparation; LMP: conception and coordination of the study, performed genotyping of samples and laboratory assays, main supervisor, critical revision and final approval of the article. All Authors approved the final version of the manuscript.

\section{Acknowledgements}

The study was fincanced by the "Iuliu Hatieganu" University of Medicine and Pharmacy Cluj-Napoca for Doctoral Research Projects (DRP) 2016, no. 7690/26 of 15.04.2016 and DRP 2017, no. 5200/24 of 1.03.2017.

\section{References}

1 Procopciuc LM, Sitar-Tăut A, Pop D, Sitar-Tăut D, Olteanu I and Zdrenghea D: Renin angiotensin system polymorphisms in patients with metabolic syndrome (MetS). Eur J Internal Med
21: 414-418, 2010. PMID: 20816596. DOI: 10.1016/j.ejim. 2010.06 .001

2 Radulescu D, Stoicescu L, Buzdugan E and Donca V: Patterns of left ventricular remodeling among patients with essential and secondary hypertension. Rev Med Chil 141(12): 1520-1527, 2013. PMID: 24728428. DOI: 10.4067/s0034-988720130120004

3 Dawber TR: The Framingham Study: The Epidemiology of Atherosclerotic Disease. Cambridge, Mass, Harvard University Press, pp. 91-119, 1980.

4 Petkeviciene J, Klumbiene J, Simonyte S, Ceponiene I, Jureniene K, Kriaucioniene V and Lesauskaite V: Physical, behavioural and genetic predictors of adult hypertension: The findings of the Kaunas Cardiovascular Risk Cohort study. PLoS ONE 9(10), 2014. PMID: 25313554. DOI: 10.1371/journal.pone.0109974

5 Forgo B, Medda E, Hernyes A, Szalontai L, Tarnoki DL and Tarnoki AD: Carotid artery atherosclerosis: A review on heritability and genetics. Twin Res Hum Genet 21(5): 333-346, 2018. PMID: 29976271. DOI: 10.1017/thg 2018.45

6 Wang X, Li W, Song F, Wang L, Fu Q, Cao S, Gan Y, Zhang W, Yue W, Yan F, Shi W, Wang X, Zhang H, Zhang H, Wang Z and Lu Z: Carotid atherosclerosis detected by ultrasonography: A national cross-sectional study. J Am Heart Assoc 7(8), 2018. PMID: 29622590. DOI: 10.1161/JAHA.118.008701

7 Cozma A, Taut AS, Orasan O, Lucia Maria Procopciuc, Anca Farcas, Adina Stan, Vasile Negrean, Dorel Sampelean, Dana Pop, Dumitru Zdrenghea and Adriana Fodor: The relationship between eNOS (G894T) gene polymorphism and arterial stiffness in patients with metabolic syndrome. Rev Chim 69(9): 2351-2356, 2018. DOI: 10.37358/rc.18.9.6532

8 Pavlyushchik O, Afonin V, Fatykhava S, Shabunya P, Sarokina $\mathrm{V}$ and Khapaliuk A: Macro- and microelement status in animal and human hypertension: The role of the ACE gene I/D polymorphism. Biol Trace Elem Res 180(1): 110-119, 2017. PMID: 28303511. DOI: 10.1007/s12011-017-0990-6

9 Van Den Born BJH, Van Montfrans GA, Uitterlinden AG, Zwinderman $\mathrm{AH}$ and Koopmans RP: The M235T polymorphism in the angiotensinogen gene is associated with the risk of malignant hypertension in white patients. J Hypertens 25(11): 2227-2233, 2007. PMID: 17921816. DOI: 10.1097/HJH 0b013e3282efb213

10 Mustafina LJ, Naumov VA and Cieszczyk P: AGTR2 gene polymorphism is associated with muscle fibre composition, athletic status and aerobic performance. Exp Physiol 99(8): 1042-1052, 2014. PMID: 24887114. DOI:10.1113/expphysiol. 2014.079335

11 Muñoz-Durango N, Fuentes CA and Castillo AE: Role of the renin-angiotensin-aldosterone system beyond blood pressure regulation: Molecular and cellular mechanisms involved in endorgan damage during arterial hypertension. Int J Mol Sci 17(7): 1-17, 2016. PMID: 27347925. DOI:10.3390/ijms 17070797

12 Yuan J, Tang W, Chun Y, Ying H, Yang Y and Xiao C: Angiotensinogen T174M and M235T variants and hypertension in the hani and Yi minority groups of China. Biochem Genet 47(5-6): 344-350, 2009. PMID: 19365726. DOI: 10.1007/ s10528-009-9237-3

13 Arumugam S, Sreedhar R, Thandavarayan R, Karuppagounder V, Krishnamurthy P, Suzuki K, Nakamura M and Watanabe K: Angiotensin receptor blockers: focus on cardiac and renal injury. Trends Cardiovasc Med 26(3): 221-228, 2016. PMID: 26169314. DOI: $10.1016 / \mathrm{j} . \mathrm{tcm} .2015 .06 .004$ 
14 Mohana VU, Swapna N, Surender RS, Vishnupriya S and Padma T: Gender-related association of AGT gene variants (M235T and T174M) with essential hypertension-A case-control study. Clin Exp Hypertens 34(1): 38-44, 2012. PMID: 22148914. DOI: 10.3109/10641963.2011.618207

15 Procopciuc LM, Nemeti G, Buzdugan E, Iancu M, Stamatian F and Caracostea G: Renin-angiotensin system gene variants and risk of early- and late-onset preeclampsia: A single center casecontrol study. Pregnancy Hypertens 18: 1-8, 2019. PMID: 31442828. DOI: $10.1016 /$ j.preghy.2019.08.006

16 Lin J, Lin S, Wu Y, Wang X, Wu S and Li H: Hypomethylation of the angiotensin II type I receptor (AGTR1) gene along with environmental factors increases the risk for essential hypertension. Cardiol 137(2): 126-135, 2017. PMID: 28376480. DOI: $10.1159 / 000458520$

$17 \mathrm{Wu}$ CK, Lee JK and Lin LY: Renin-angiotensin system genes polymorphisms and long-term prognosis in Taiwanese patients with hypertension and coronary artery disease. Acta Cardiol Sin 29(1): 28-36, 2013. PMID: 27122682. DOI: 10.1093/eurhartj/ eht308.1830

18 Das S, Roy S, Sharma V, Kaul S, Jyothy A and Munshi A: Association of ACE gene I/D polymorphism and ACE levels with hemorrhagic stroke: comparison with ischemic stroke. Neurol Sci 36(1): 137-142, 2014. PMID: 25015258. DOI: 10.1007/s10072-0141880-8

19 Chen X, Howatt DA, Balakrishnan A, Moorleghen JJ, Wu C, Cassis LA, Daugherty A and Lu H: Angiotensin-converting enzyme in smooth muscle cells promotes atherosclerosis-Brief report. Arterioscler Thromb Vasc Biol 36(6): 1085-1089, 2016. PMID: 27055902. DOI: 10.1161/ATVBAHA.115.307038

20 Stanković A, Kolaković A, Živković M, Djurić T, Bundalo M, Končar I, Davidović L and Alavantić D: Angiotensin receptor type 1 polymorphism A1166C is associated with altered AT1R and miR-155 expression in carotid plaque tissue and development of hypoechogenic carotid plaques. Atherosclerosis 248: 132-92, 2016. PMID: 27016615. DOI: 10.1016/ jatherosclerosis.2016.02.032.

21 Bonfim-Silva R, Guimarães LO, Santos JS, Pereira JF, Leal Barbosa AA and Souza Rios DL: Case-control association study of polymorphisms in the angiotensinogen and angiotensinconverting enzyme genes and coronary artery disease and systemic artery hypertension in African-Brazilians and Caucasian-Brazilians. J Genet 95(1): 63-69, 2016. PMID: 27019433. DOI: $10.1007 / \mathrm{s} 12041-015-0599-5$

22 Procopciuc L, Popescu T, Jebeleanu G, Pop D and Zdrenghea D: Essential arterial hypertension and polymorphism of angiotensinogen M235T gene. J Cell Mol Med 6(2): 245-250, 2002. PMID: 12169209. DOI: 10.1111/j.1582-4934.2002.tb00191.x

23 Zotova Y, Lapaev $\mathrm{N}$ and Azova M: Distribution of polymorphisms of the renin-angiotensin system genes (ACE, AGT, and AGTR1), ITGB3, and FTO in pregnant patients with hypertensive disorders. Bull Exp Biol Med 167(1): 74-78, 2019. PMID: 31177447. DOI: 10.1007/s10517019-04464-6

24 Sousa A, Palma dos Reis R, Pereira A and Borges S: Genetic polymorphisms associated with the onset of arterial hypertension in a Portuguese population. Acta Medica Portuguesa 31(10): 542-550, 2018. PMID: 30387422. DOI: 10.20344/amp.9184

25 Fountain JH and Lappin SL: Physiology, renin angiotensin system. In: StatPearls, Treasure Island, FL, USA: StatPearls Publishing, 2019. PMID: 29261862.
26 Isordia-Salas I, Santiago-Germán D, Cerda-Mancillas MC, Hernández-Juárez J, Bernabe-García M, Leaños-Miranda A, Alvarado-Moreno JA and Majluf-Cruz A: Gene polymorphisms of angiotensin-converting enzyme and angiotensinogen and risk of idiopathic ischemic stroke. Gene 688: 163-170, 2019. PMID: 30521887. DOI: 10.1016/j.gene. 2018.11.080

27 Van der Laan S, Siemelink M, Haitjema S, Foroughi AH and Perisic L: Genetic susceptibility loci for cardiovascular disease and their impact on atherosclerotic plaques. Circ Genom Precis Med 11(9): 1-11, 2018. PMID: 30354329. DOI: 10.1161/ CIRCGEN.118.002115

28 Xia MM, Wang M and Jiang H: Association of angiotensinconverting enzyme insertion/deletion polymorphism with the risk of atherosclerosis. J Stroke Cerebrovasc Dis 28(6): 1732-1743, 2019. PMID: 30878369. DOI: 10.1016/j.jstrokecerebrovasdis.2019.02.012

29 Bautista LE, Vargas CI, Oróstegui M and Gamarra G: Population-based case-control study of renin-angiotensin system genes polymorphisms and hypertension among Hispanics. Hypertens Res 31(3): 401-408, 2008. PMID: 18497458. DOI: 10.1291/hypres.31.401

30 Mehri S, Mahjoub S, Hammami S, Zaroui A, Frih A and Betbout F: Renin-angiotensin system polymorphisms in relation to hypertension status and obesity in a Tunisian population. Mol Biol Rep 39(4): 4059-4065, 2012. PMID: 21779803. DOI: 10.1007/s11033-011-1187-2

31 Guney AI, Ergec D, Kirac D, Ozturhan H, Caner M and Koc G: Effects of ACE polymorphisms and other risk factors on the severity of coronary artery disease. Genet Mol Res 12(4): 68956906, 2013. PMID: 24391037. DOI: 10.4238/2013.

32 Moradzadegan A, Vaisi-Raygani A, Nikzamir A and Rahimi Z: Angiotensin-converting enzyme insertion/deletion (I/D) (rs4646994) and Vegf polymorphism (+405G/C; rs2010963) in type II diabetic patients: association with the risk of coronary artery disease. J. Renin Angiotensin Aldosterone Sys 16(3): 672680, 2014. PMID: 24505095. DOI: 10.1177/1470320313497819

33 Pandey U, Kumari R, Nath B, Ganesh S, Banerjee I and Hasan OM: Association of angiotensin-converting enzyme, methylene tetrahydrofolate reductase and paraoxonase gene polymorphism and coronary artery disease in an Indian population. Cardiol J 18(4): 385-394, 2011. PMID: 21769819.

34 Ned RM, Yesupriya A, Imperatore G, Smelser DT, Moonesinghe $\mathrm{R}$ and Chang MH: The ACE I/D polymorphism in US adults: limited evidence of association with hypertension-related traits and sex-specific effects by race/ethnicity. Am J Hypertens 25(2): 209-215, 2012. PMID: 21993364. DOI: 10.1038/ajh.2011.182

35 Tsai CT, Hwang JJ, Ritchie MD, Moore JH, Chiang FT and Lai LP: Renin-angiotensin system gene polymorphisms and coronary artery disease in a large angiographic cohort: detection of high order gene-gene interaction. Atherosclerosis 195(1): 172-180, 2011. PMID: 17118372. DOI: 10.1016/j.atherosclerosis.2006.09.014

36 Ludwig EH, Borecki IB, Ellison RC, Folsom AR, Heiss G, Higgins M, Lalouel JM, Province MA and Rao DC: Associations between candidate loci angiotensin convertiting enzyme and angiotensinogen with coronary heart disease and myocardial infarction: The NHLBI Family Heart Study. Ann Epidemiol 7(1): 3-12, 1997. PMID: 9034401. DOI: 10.1016/s1047-2797(96)00105-6

37 Araújo MA, Goulart LR and Cordeiro ER: Genotypic interactions of renin-angiotensin system genes in myocardial infarction. Int J Cardiol 103(1): 27-32, 2005. PMID: 16061119. DOI: $10.1016 /$ j.ijcard.2004.07.009 
38 Hazzani A, Daoud MS, Ataya FS, Fouad D and Al-Jafari AA: Renin-angiotensin system gene polymorphisms among Saudi patients with coronary artery disease. J Biol Res 21(1): 1-9, 2014. PMID: 25984491. DOI: 10.1186/2241-5793-21-8

39 Min Z, Lin J and Wang C: The relationship among angiotensinogen genes polymorphisms and hs-CRP and coronary artery disease. J Clin Lab Anal 33(5): 1-7, 2019. PMID: 30912862. DOI: $10.1002 /$ jcla.22881

40 Jeng JR: Left ventricular mass, carotid wall thickness, and angiotensinogen gene polymorphism in patients with hypertension. Am J Hypertens 12(5): 443-450, 1999. PMID: 10342781. DOI: 10.1016/S0895-7061(99)00006-0.

41 Pontremoli R, Ravera M and Viazzi F: Genetic polymorphism of the renin-angiotensin system and organ damage in essential hypertension. Kidney Int 57(2): 561-569, 2000. PMID: 10652033. DOI: $10.1046 / j .1523-1755.2000 .00876 . x$

42 Chapman CML, Palmer LJ and McQuillan BM: Polymorphisms in the angiotensinogen gene are associated with carotid intimalmedial thickening in females from a community-based population. Atherosclerosis 159(1): 209-217, 2001. PMID: 11689223. DOI: 10.1016/S0021-9150(01)00499-3

43 Van Rijn MJE, Bos MJ and Isaacs A: Polymorphisms of the renin-angiotensin system are associated with blood pressure, atherosclerosis and cerebral white matter pathology. J Neurol Neurosurg Psychiatry 78(10): 1083-1087, 2007. PMID: 17220293. DOI:10.1136/jnnp.2006.109819

44 Kretowski A, McFann K and Hokanson JE: Polymorphisms of the renin-angiotensin system genes predict progression of subclinical coronary atherosclerosis. Diabetes 56(3): 863-871, 2007. PMID: 17327458. DOI:10.2337/db06-1321

45 Bao C, Sun X, Zhu Y, Du Y, Cui J, Ma L and Cai J: Relationship between angiotensin converting enzyme gene polymorphism and carotid atherosclerotic plaque: A study based on vessel wall magnetic resonance imaging. Zhongguo Yi Xue Ke Xue Yuan Xue Bao 40(4): 493-500, 2018. PMID: 30193603. DOI: $10.3881 / \mathrm{j}$.issn.1000-503X.10044

46 Zhang JH, Kohara K and Yamamoto Y: Genetic predisposition to neurological symptoms in lacunar infarction. Cerebrovasc Dis 17(4): 273-279, 2004. PMID: 15026609. DOI:10.1159/ 000077337
47 Islam MS, Lehtimäki T and Juonala M: Polymorphism of the angiotensin-converting enzyme (ACE) and angiotesinogen (AGT) genes and their associations with blood pressure and carotid artery intima media thickness among healthy Finnish young adults-The Cardiovascular Risk in Young Finns Study. Atherosclerosis 188(2): 316-322, 2006. PMID: 16387306. DOI: 10.1016/j.atherosclerosis.2005.11.008

48 Arnett DK, Borecki IB and Ludwig EH: Angiotensinogen and angiotensin converting enzyme genotypes and carotid atherosclerosis: The atherosclerosis risk in communities and the NHLBI family heart studies. Atherosclerosis 138(1): 111-116, 1998. PMID: 9678776. DOI: 10.1016/S0021-9150(98)00009-4

49 Targher G, Bertolini L, Padovani R, Rodella S and Zoppini G: Relations between carotid artery wall thickness and liver histology in subjects with nonalcoholic fatty liver disease. Diabetes Care 29(6): 1325-1330, 2006. PMID: 16732016. DOI: 10.2337/dc06-0135

50 Liu A, Yu Z, Wang N and Wang W: Carotid atherosclerosis is associated with hypertension in a hospital-based retrospective cohort. Int J Clin Exp Med 8(11): 21932-21938, 2015. PMID: 26885164.

51 Condur L, Lilios E and Lilios G: Correlation between risk factors and prognostic biomarkers in high blood pressure. Available at: https://www.medichub.ro/reviste/medicro/corelatia-dintre-factorii-de-risc-si-biomarkerii-de-prognosticin-hipertensiunea-arteriala-id-291-cmsid-51

52 Kanazawa I and Sugimoto T: Prehypertension increases the risk of atherosclerosis in drug-naïve Japanese patients with type 2 diabetes mellitus. Plos One 13(7): 1-10, 2018. PMID: 30028862. DOI: 10.1371/journal.pone.0201055
Received May 2, 2020

Revised May 14, 2020

Accepted May 16, 2020 